Gomez-Rubio, P., Zock, J.P., Rava, M., Marquez, M., Sharp, L., Hidalgo, M., Carrato, A., Ilzarbe, L., Michalski, C., Molero, X., Farré, A., Perea, J., Greenhalf, W., O’Rorke, M., Tardón, A., Gress, T., Barbera, V., Crnogorac-Jurcevic, T., Dominguez-Munoz, E., Munoz-Bellvis, L., Alvarez-Itrturi,7 C., Balcells, J., Barneo, L., Costello, E., Guillen-Ponce, C., Kleeff, J., Kong, B., Lawlor, R., LP̈hlve M., Mora, J., Murray, L., O'Driscoll, D., Pelaez, P., Poves, I., Scarpa, A., Real, F.X., Malats, N. Reduced risk of pancreatic cancer associated with asthma and nasal allergies. Gut: 2017, 66(2), 314-322

\begin{tabular}{|l|l|}
\hline $\begin{array}{l}\text { Postprint } \\
\text { Version }\end{array}$ & 1.0 \\
\hline Journal website & $\underline{\text { http://dx.doi.org/10.1136/gutjnl-2015-310442 }}$ \\
\hline Pubmed link & $\underline{\text { http://www.ncbi.nlm.nih.gov/pubmed/26628509 }}$ \\
\hline DOI & $10.1136 /$ gutjnl-2015-310442 \\
\hline
\end{tabular}

This is a NIVEL certified Post Print, more info at http://www.nivel.eu

\title{
Reduced risk of pancreatic cancer associated with asthma and nasal allergies
}

\author{
Paulina Gomez-Rubio1, Jan-PAul Zock2, Marta RaVa1, Mirari Marquez1, Linda \\ Sharp3, MANUEl HidAlgO4, AlFredo CARRATO5, LuCAS IlZARbe6, ChristopH \\ Michalski7, XAVIER Molero8,ANTONI FARRÉ9, JosÉ PEREA10, WiLliaM \\ GREENHALF11, MichaEl O'RORKE12, AdONINA TARDÓN13, THOMAS GRESS14, ViCTOR \\ BARBERÀ15, TATJANA CRNOGORAC-JURCEVIC16,ENRIQUE DOMÍNGUEZ-MUÑOZ17, LuÍS \\ MUÑOZ-BELlVÍs18, CRISTINA ALVAREZ-URTURI6,JOAQUIM BALCELLS8, LUIS \\ BARNEO13, EITHNE COSTELlO11, CARMEN GUILlÉN-PONCE5, JÖRG KLEEFF7, BO \\ KONG7, RitA LAWLOR19, MATTHIAS LÖHR20, JOSEFINA MORA9, LIM \\ Murray12, Damian O'Driscoll3,PABlo Peláez10, Ignasi Poves6, Aldo \\ SCARPA19, Francisco X REAL21, NúRIA MALATS1 PANGENEU STUdY \\ INVESTIGATORS22
}

1 Genetic and Molecular Epidemiology Group, Spanish National Cancer Research Center (CNIO), Madrid, Spain

2Centre for Research in Environmental Epidemiology (CREAL), Barcelona, Spain

3National Cancer Registry Ireland, Cork, Ireland, and Institute of Health \& Society,Newcastle

University, UK

4Hospital Madrid-Norte-Sanchinarro, Madrid, Spain

5Department of Oncology, Hospital Ramón y Cajal, Madrid, Spain

6 Hospital del Mar-Parc de Salut Mar, Barcelona, Spain

7Technical University of Munich, Munich, Germany

8Exocrine Pancreas Research Unit, Hospital Universitari Vall d'Hebron, Barcelona, Spain

9 Hospital de la Santa Creu i Sant Pau, Barcelona, Spain

10Department of Surgery, 12 de Octubre University Hospital, Madrid, Spain

11The Royal Liverpool University Hospital, Liverpool, UK

12Centre for Public Health, Queen's University Belfast, Belfast, UK

13 Instituto Universitario de Oncología del Principado de Asturias, Oviedo, Spain

14Department of Gastroenterology, University Hospital Giessen and Marburg, Marburg,

Germany

15Laboratorio de Genética Molecular, Hospital General Universitario de Elche, Elche, Spain

16Centre for Molecular Oncology, Barts Cancer Institute, Queen Mary University of

London,London, UK

17Hospital Clínico Universitario de Santiago de Compostela, Santiago de Compostela,

Spain

18Cirugía General y del Aparato Digestivo, Hospital Universitario de Salamanca,Salamanca,

Spain

19Department of Pathology and Diagnostics, University of Verona, Verona, Italy

20Gastrocentrum, Karolinska Institutet, Stockholm, Sweden

21Epithelial Carcinogenesis Group, Spanish National Cancer Research Centre

(CNIO),Madrid, Spain 
Gomez-Rubio, P., Zock, J.P., Rava, M., Marquez, M., Sharp, L., Hidalgo, M., Carrato, A., Ilzarbe. L., Michalski, C., Molero, X., Farré, A., Perea, J., Greenhalf, W., O’Rorke, M., Tardón, A., Gress, T., Barbera, V., Crnogorac-Jurcevic, T., Dominguez-Munoz, E., Munoz-Bellvis, L., Alvarez=Itrturi,7 C., Balcells, J., Barneo, L., Costello, E., Guillen-Ponce, C., Kleeff, J., Kong, B., Lawlor, R., LP̈hlve M., Mora, J., Murray, L., O'Driscoll, D., Pelaez, P., Poves, I., Scarpa, A., Real, F.X., Malats, N. Reduced risk of pancreatic cancer associated with asthma and nasal allergies. Gut: 2017, 66(2), 314-322

22List of PanGenEU Study Investigators is in Supplementary Annex

\begin{abstract}
Objective Studies indicate an inverse association between ductal adenocarcinoma of the pancreas (PDAC) and nasal allergies. However, controversial findings are reported for the association with asthma. Understanding PDAC risk factors will help us to implement appropriate strategies to prevent, treat and diagnose this cancer. This study assessed and characterised the association between PDAC and asthma and corroborated existing reports regarding the association between allergies and PDAC risk.

Design Information about asthma and allergies was collated from 1297 PDAC cases and 1024 controls included in the PanGenEU case-control study. Associations between PDAC and atopic diseases were studied using multilevel logistic regression analysis. Meta-analyses of association studies on these diseases and PDAC risk were performed applying random-effects model.

Results Asthma was associated with lower risk of PDAC (OR 0.64, 95\% CI 0.47 to 0.88 ), particularly long-standing asthma (>=17 years, OR $0.39,95 \%$ CI 0.24 to 0.65 ). Meta-analysis of 10 case-control studies sustained our results (metaOR $0.73,95 \%$ CI 0.59 to 0.89 ). Nasal allergies and related symptoms were associated with lower risk of PDAC (OR $0.66,95 \%$ CI 0.52 to 0.83 and OR $0.59,95 \%$ CI 0.46 to 0.77 , respectively). These results were supported by a meta-analysis of nasal allergy studies (metaOR 0.6, 95\% CI 0.5 to 0.72). Skin allergies were not associated with PDAC risk.

Conclusions This study shows a consistent inverse association between PDAC and asthma and nasal allergies, supporting the notion that atopic diseases are associated with reduced cancer risk. These results point to the involvement of immune and/or inflammatory factors that may either foster or restrain pancreas carcinogenesis warranting further research to understand the molecular mechanisms driving this association.
\end{abstract}

\title{
SIGNIFICANCE OF THIS STUDY
}

\section{What is already known on this subject?}

There is an important lack of knowledge on pancreatic cancer aetiology and its associated factors, both environmental and genetic.

Present knowledge points to a role of chronic inflammation in pancreas carcinogenesis.

Nasal allergies are associated with decreased risk of pancreatic cancer.

Studies on the association between asthma and pancreatic cancer are inconclusive. There is a need of studies that accurately characterise asthma, allowing for a more reliable assessment of the association between this exposure and pancreatic cancer risk. 
Gomez-Rubio, P., Zock, J.P., Rava, M., Marquez, M., Sharp, L., Hidalgo, M., Carrato, A., Ilzarbe L., Michalski, C., Molero, X., Farré, A., Perea, J., Greenhalf, W., O’Rorke, M., Tardón, A., Gress, T., Barbera, V., Crnogorac-Jurcevic, T., Dominguez-Munoz, E., Munoz-Bellvis, L., Alvarez-Iłrturi,7 C., Balcells, J., Barneo, L., Costello, E., Guillen-Ponce, C., Kleeff, J., Kong, B., Lawlor, R., LP̈hKVe M., Mora, J., Murray, L., O'Driscoll, D., Pelaez, P., Poves, I., Scarpa, A., Real, F.X., Malats, N. Reduced risk of pancreatic cancer associated with asthma and nasal allergies. Gut: 2017, 66(2), 314-322

\section{What are the new findings?}

Asthma, asthma severity and duration are significantly associated with a lower risk of pancreatic cancer.

Meta-analysis of 10 case-control studies further support the inverse association of asthma with pancreatic cancer risk.

Nasal allergies and its symptoms are also consistently associated with reduced pancreatic cancer risk.

\section{How might it impact on clinical practice in the foreseeable future?}

Combining precise data on pancreatic ductal adenocarcinoma risk and protective factors, including atopic diseases, would allow building accurate risk prediction models to potentially discriminate high-risk individuals from the general population, those deserving to be entered in primary prevention interventions and screening programmes.

Understanding the mechanism through which atopic diseases associate with pancreatic cancer will shed light into the inflammatory aetiology of this cancer and might support primary prevention interventions and treatments by modulating such mechanisms in high-risk populations and patients, respectively.

\section{INTRODUCTION}

In the USA, it is projected that pancreatic cancer mortality will become the second leading cause of cancer-related deaths before 2030.1 In Europe, this is the only cancer for which death rates increased in both genders in 2014.2 Pancreatic ductal adenocarcinoma (PDAC), representing $95 \%$ of pancreatic cancers, is a rare disease with a 5-year relative survival rate of $<4 \% .3$ To date, our understanding of PDAC aetiology is still limited. Among the risk factors of PDAC, several medical conditions have been extensively studied, including chronic pancreatitis, obesity and type II diabetes (T2D), which have been consistently associated with an increased risk of PDAC4, 5 pointing to a chronic inflammatory hypothesis. In addition, under the assumption of a participation of the immune system in the disease development, epidemiological studies have explored the association between allergic disorders and PDAC risk.6,7 A meta-analysis published in 2005 included 14 case-control and cohort studies summarising initial reports on the subject.6,8-20 In this metaanalysis, pooled estimates showed a significantly reduced risk of PDAC in subjects reporting having any allergy, nasal allergies or skin allergies, but there was no association with a history of asthma. Other reports have largely replicated the inverse association between PDAC and nasal allergies with only one study reporting a nonsignificant reduced estimate.21-25 Regarding skin allergies, two additional articles reported reduced estimates but only one showed statistical significance.24,25Conversely, the association between asthma and PDAC risk has remained inconclusive. From the 12 studies that have evaluated this association, 3 resulted in a significant association between asthma and PDAC risk; however, 2 of them reported a negative association while the other reported a positive association.9,11-13, 15, 16,18, 19,21,24-26 These inconsistencies can be explained, in part, by the difficulties in the correct assessment of the asthma 
Gomez-Rubio, P., Zock, J.P., Rava, M., Marquez, M., Sharp, L., Hidalgo, M., Carrato, A., Ilzarbe L., Michalski, C., Molero, X., Farré, A., Perea, J., Greenhalf, W., O’Rorke, M., Tardón, A., Gress, T., Barbera, V., Crnogorac-Jurcevic, T., Dominguez-Munoz, E., Munoz-Bellvis, L., Alvarez-Iłrturi,7 C., Balcells, J., Barneo, L., Costello, E., Guillen-Ponce, C., Kleeff, J., Kong, B., Lawlor, R., LP̈hKVe M., Mora, J., Murray, L., O'Driscoll, D., Pelaez, P., Poves, I., Scarpa, A., Real, F.X., Malats, N. Reduced risk of pancreatic cancer associated with asthma and nasal allergies. Gut: 2017, 66(2), 314-322

phenotype and the relative small sample size of the studies, mainly in the case groups.

Because of the importance of understanding factors associated with PDAC development, we looked to corroborate existing reports regarding allergies and PDAC risk and aimed at evaluating the association between PDAC and asthma by using a targeted set of questions that provided a more reliable assessment of atopic diseases. This assessment was performed within the PanGenEU, a European casecontrol study, with the largest set of cases examined for this association so far.

\section{METHODS}

\section{Study population}

Participants were recruited in the PanGenEU case-control study between 2009 and 2014. The PanGenEU is an ongoing study that was designed to recruit 2000 cases and 2000 controls from centres in England, Germany, Ireland, Italy, Spain and Sweden (see online supplementary annex). Men and women above 18 years of age were eligible. To reduce ascertainment and information biases resulting from the very poor prognosis of this disease, all identified suspected PDAC cases were approached for participation in the study. After physician's confirmation of the diagnosis, subjects not diagnosed with PDAC were excluded.

Controls were recruited from a hospital-based setting in all countries with the exception of Ireland, where controls were population based. Eligible controls did not have history of PDAC and hospital-based controls were eligible if their principal diagnosis was not related to any risk factor of PDAC (see online supplementary table $1)$.

This study reports the findings on 1297 cases and 1024 controls included in the English, German, Irish and Spanish centres.

\section{Information}

Information was collected through direct in-person interviews performed by trained health monitors applying the same protocol and structured questionnaire that includes detailed information about lifestyle, environmental exposures and medical history. The questionnaire included 18 questions about atopic diseases and their symptoms. These questions are a subset of the standardised questionnaire developed by the European Community Respiratory Health Survey for the study of asthma and allergies that have been validated in the participating countries.27,28 Detailed description of all atopic diseases variables is shown in table 1.

\section{[TABLE 1]}

Other information considered for model adjustment were age and years of education (continuous), body mass index calculated using weight 2 years before recruitment and usual adult height $(\mathrm{kg} / \mathrm{m} 2$, underweight and normal weight/overweight/obese), smoking status (never/former/current), smoking pack/years (tertiles based on population distribution), alcohol consumption (never/ever), periodontitis (no/yes), T2D (never/diagnosed 2 years within recruitment/diagnosed $>2$ years before recruitment) and chronic pancreatitis (no/yes). 
Gomez-Rubio, P., Zock, J.P., Rava, M., Marquez, M., Sharp, L., Hidalgo, M., Carrato, A., Ilzarbe. L., Michalski, C., Molero, X., Farré, A., Perea, J., Greenhalf, W., O’Rorke, M., Tardón, A., Gress, T., Barbera, V., Crnogorac-Jurcevic, T., Dominguez-Munoz, E., Munoz-Bellvis, L., Alvarez-Iłrturi,7 C., Balcells, J., Barneo, L., Costello, E., Guillen-Ponce, C., Kleeff, J., Kong, B., Lawlor, R., LP̈hKVe M., Mora, J., Murray, L., O'Driscoll, D., Pelaez, P., Poves, I., Scarpa, A., Real, F.X., Malats, N. Reduced risk of pancreatic cancer associated with asthma and nasal allergies. Gut: 2017, 66(2), 314-322

\section{Statistical analysis}

To avoid potential bias resulting from complete-case analysis, imputation was performed using missForest package. 29 Based on the distribution of missing counts ( $4.3 \%$ in cases and $3 \%$ in controls), data were assumed to be missing at random. Imputation was performed using case-control status, centre, country, age, sex, smoking status, pack/years, T2D, chronic pancreatitis, nasal allergies, nasal allergies' detailed phenotype, skin allergies, skin allergies' detailed phenotype, asthma, asthma medication, asthma age of onset, asthma score and asthma duration (description of atopic variables in table 1). Imputation was performed with no maximum number of iterations and with 100 trees. Performance was evaluated using out of bag (OOB) error rates: normalised squared error for continuous variables and proportion of falsely classified entries for categorical variables (values close to zero indicated good performance and values close to one indicated bad performance). Data imputation OOB estimates were $<0.34$ (mean: $0.14,95 \%$ CI 0.07 to 0.2 ). Prevalences of atopic diseases were calculated adjusting for sex and age category $(<54,55-64,65-74,>75$; online supplementary table S2). Prevalences before and after imputation were compared using the test of equality of proportions.

OR estimates and 95\% CIs were estimated with multilevel logistic regression using lme4 package to evaluate subject-level factors while accounting for clustering within country. Stepwise regression was used for confounder selection considering the aforementioned variables. Median OR was calculated to measure between country variability.30 Potential effect modifications by sex and smoking were tested by including sex and pack/years as interaction terms in the regression models. All statistical analyses were performed as two-sided test using R V.3.1.2.31

\section{Meta-analysis}

Studies on the association between atopic diseases and PDAC risk were searched in PubMed and Web of Science using the following terms: 'asthma' or 'allergy' or 'medical history' and 'pancreas cancer' or 'pancreatic cancer'. All epidemiological studies reporting separately on these diseases and using similar phenotype definitions were selected regardless of the year of publication. Dai et al16 was found through the reference list of other publications. Pooled estimates and heterogeneity among studies were calculated using the metafor package by random-effects meta-analysis and Cochran's Q-test, respectively.

\section{RESULTS}

Characteristics of the subjects are listed in table 2. Study subjects with written consent and available questionnaire data consisted in 1297 cases and 1024 controls of the initial eligible 1975 cases and 1554 controls. Reasons for no participation in the study were recorded for all subjects not included in the study. Proportion of males was slightly higher than females in both cases and controls. Average age was 65.3 years old (SD 12.4). Most of the study population was recruited in Spain (62.8\%), followed by Ireland (19.9\%), Germany (10.9\%) and England (6.4\%). 
Gomez-Rubio, P., Zock, J.P., Rava, M., Marquez, M., Sharp, L., Hidalgo, M., Carrato, A., Ilzarber L., Michalski, C., Molero, X., Farré, A., Perea, J., Greenhalf, W., O’Rorke, M., Tardón, A., Gress, T., Barbera, V., Crnogorac-Jurcevic, T., Dominguez-Munoz, E., Munoz-Bellvis, L., Alvarez-Itrturi,7 C., Balcells, J., Barneo, L., Costello, E., Guillen-Ponce, C., Kleeff, J., Kong, B., Lawlor, R., LP̈hlve M., Mora, J., Murray, L., O'Driscoll, D., Pelaez, P., Poves, I., Scarpa, A., Real, F.X., Malats, N. Reduced risk of pancreatic cancer associated with asthma and nasal allergies. Gut: 2017, 66(2), 314-322

\section{[TABLE 2]}

Prevalences of atopic diseases for each country are summarised in online supplementary table $\mathrm{S} 2$. No significant differences were observed between imputed and non-imputed data $(\mathrm{p}>0.75)$. Since prevalence of nasal and skin allergies differed between cases and controls in England, we performed a sensitivity analysis removing England from the study. Only slight changes were observed and the direction and significance of the associations were not altered; therefore, we report on the analysis of the whole population.

Table 3 shows the distribution of allergy and asthma phenotypes in cases and controls and their estimates for PDAC risk. Since similar estimates were obtained from univariate and multivariate multilevel models, we only report multivariate results. Nasal allergies were associated with reduced risk of PDAC (OR 0.66, 95\% CI 0.52 to 0.83 ). Specific nasal allergy symptoms including the year before recruitment (table 1) were associated with decreased risk of PDAC (OR 0.59, 95\% CI 0.46 to 0.77 ), while symptoms occurring more than a year before recruitment were not associated with risk (OR $1.09,95 \%$ CI 0.76 to 1.59 ). Ever having had skin allergies was not associated with PDAC risk (OR 0.95, 95\% CI 0.78 to 1.17). Having had skin allergy symptoms including the year before recruitment was associated with high risk of PDAC; a significant association was observed when those symptoms were reported in atopic-related body parts (OR 2.47, 95\% CI 1.60 to 3.81).

\section{[TABLE 3]}

Among self-reported asthmatics, $91 \%$ reported confirmation by their doctor. Ever having had asthma was associated with significantly reduced risk of PDAC (OR $0.64,95 \%$ CI 0.47 to 0.88 ), as well as asthma duration ( $\mathrm{p}$ trend $=0.0002$ ). Having asthma for $>=17$ years showed the lowest risk of PDAC (OR $0.39,95 \%$ CI 0.24 to 0.65). Current asthma medication use was associated with decreased risk of PDAC (OR $0.47,95 \%$ CI 0.31 to 0.69 ), while not currently taking asthma medication was not. Reduced estimates were observed regardless of asthma age of onset; however, this was significant only for onset $>=16$ years (OR $0.65,95 \%$ CI 0.47 to 0.91 ). Subjects with asthma score $>=2$ showed a significantly reduced risk of PDAC (OR $0.49,95 \%$ CI 0.34 to 0.71 ). A significant risk reduction trend was also observed when analysing the score as a continuum $(\mathrm{p}=0.0002)$.

Subjects reporting having only asthma or only nasal allergies were significantly associated with lower risk of PDAC (OR $0.55,95 \%$ CI 0.38 to 0.81 and OR 0.62 , 95\% CI 0.48 to 0.79 , respectively). Having both diseases resulted in a reduced, though non-significant, estimate (OR 0.69, 95\% CI 0.42 to 1.13). All associations were assessed for interaction with sex and smoking, but no significant effect modification was observed (data not shown).

Due to the small number of prospective cohort studies reporting on atopic diseases and PDAC, the differences between populations and variable definitions, we did not consider it appropriate to perform meta-analysis using these studies. Therefore, we report only on case-control studies. Details of the publications are provided in online supplementary tables S3-S5. Meta-analysis estimate including our results showed a significant reduced PDAC risk among asthmatics (metaOR 0.73, 95\% CI 0.59 to 0.89 , figure 1). Similarly, pooled estimates for nasal and skin allergies showed a 
Gomez-Rubio, P., Zock, J.P., Rava, M., Marquez, M., Sharp, L., Hidalgo, M., Carrato, A., Ilzarbe L., Michalski, C., Molero, X., Farré, A., Perea, J., Greenhalf, W., O’Rorke, M., Tardón, A., Gress, T., Barbera, V., Crnogorac-Jurcevic, T., Dominguez-Munoz, E., Munoz-Bellvis, L., Alvarez-Itrturi,7 C., Balcells, J., Barneo, L., Costello, E., Guillen-Ponce, C., Kleeff, J., Kong, B., Lawlor, R., LP̈hKVe M., Mora, J., Murray, L., O'Driscoll, D., Pelaez, P., Poves, I., Scarpa, A., Real, F.X., Malats, N. Reduced risk of pancreatic cancer associated with asthma and nasal allergies. Gut: 2017, 66(2), 314-322

significant reduced risk of PDAC: metaOR 0.6, 95\%CI 0.5 - 0.72, and metaOR 0.77, $95 \%$ CI 0.64 to -0.93 , respectively (figures 2 and 3 ).

\section{[FIGURE 1]}

\section{[FIGURE 2]}

\section{[FIGURE 3]}

\section{DISCUSSION}

This is the largest and more exhaustive analysis of the association between PDAC and atopic disease-related factors reported until now. We confirm the reduced risk of PDAC associated with nasal allergies and provide strong support for an inverse association between PDAC risk and asthma, including its severity and duration. The reduction of PDAC risk was stronger among asthmatics who reported currently taking asthma medication. While we cannot rule out the possibility that asthma medication could contribute to risk reduction, reporting current consumption of asthma medication not only provides confirmatory evidence of the accuracy of diagnosis but it also suggests stronger effects associated with increased disease severity. Reduced estimates were observed for both childhood and adult asthma onset, but the association was only significant for the latter group, possibly due to sample size. While most of childhood onset asthma has an atopic component, biological testing is the best way to discriminate atopic from non-atopic asthma. Given the potential biological differences underlying these two phenotypes, this area needs additional investigation.

To provide further strength to our findings, we analysed the association between asthma score and PDAC risk. Asthma score is based on asthma symptoms, allowing a more objective assessment of asthma severity. The reduction of PDAC risk was significantly associated with an increase in asthma severity. The consistency of our results is probably due to the more careful assessment of clinical phenotypes. Until now, studies evaluating the association between asthma and PDAC risk have largely yielded reduced, non-significant, estimates. One study, in the context of clinical trial of antioxidants, has reported a significant association between asthma and increased risk of PDAC.19 However, this study was small (172 PDAC cases) and recruited only male smokers aged 50-69. Similarly, another prospective study looking at the association between atopic diseases and pancreatic cancer death rate showed a nonsignificant association between self-reported asthma-only phenotype and death.26 Sample size, the questionnaire applied and the definition of the asthma phenotype may account for the discordant findings. A meta-analysis using the existing published case-control studies in combination with our results showed a significantly reduced risk of PDAC among asthmatics. Moreover, both nasal allergies and asthma were independently associated with reduced PDAC risk. Having both diseases also showed a reduced estimate, which was not significant probably due to the small sample size. Altogether, these results support the notion that asthma is inversely associated with PDAC risk. 
Gomez-Rubio, P., Zock, J.P., Rava, M., Marquez, M., Sharp, L., Hidalgo, M., Carrato, A., Ilzarbe L., Michalski, C., Molero, X., Farré, A., Perea, J., Greenhalf, W., O’Rorke, M., Tardón, A., Gress, T., Barbera, V., Crnogorac-Jurcevic, T., Dominguez-Munoz, E., Munoz-Bellvis, L., Alvarez-Itrturi,7 C., Balcells, J., Barneo, L., Costello, E., Guillen-Ponce, C., Kleeff, J., Kong, B., Lawlor, R., LP̈hlve M., Mora, J., Murray, L., O'Driscoll, D., Pelaez, P., Poves, I., Scarpa, A., Real, F.X., Malats, N. Reduced risk of pancreatic cancer associated with asthma and nasal allergies. Gut: 2017, 66(2), 314-322

Consistent with the current literature, nasal allergies were associated with a significant reduced risk of PDAC.18,21,22,25 Meta-analysis of independent studies corroborated this pattern of risk. When we detailed the nasal allergies phenotype using specific symptoms, the reduced risk of PDAC was stronger. Subjects with nasal allergy symptoms showed a reduced risk of PDAC, and considering 'itchy and watery eyes' - a typical nasal allergy symptom — in the phenotype, was associated with a further decrease in risk. We cannot rule out the possibility of reverse causation, that is, PDAC reducing nasal allergies, because the study lacks information on the age of onset of the condition. However, a previous prospective nested case-control study reported that IgE levels were not lower in pancreatic cancer cases when compared with controls. 32 Moreover, another study with smaller sample size reported high IgE serum levels in patients with PDAC,33 altogether arguing against this issue. A possible explanation for not observing a significant association among subjects reporting symptoms more than a year before recruitment is low statistical power since fewer people were assigned into this category. It is also likely that subjects report recent symptoms more accurately independently of the case-control status of the subject. This is supported by the fact that including itchy and watery eyes was associated with further risk reduction.

Concordant with other reports, we observed a non-significantly reduced PDAC risk for skin allergies.13, $14,16,25$ However, a meta-analysis of this association showed a significantly reduced risk. Subjects reporting skin allergy symptoms anytime showed a higher risk of PDAC than those who not presented symptoms during the year before recruitment. Up to $20-40 \%$ of patients with PDAC34 report severe itching due to hyperbilirubenemia, 35 thus making reverse causality a possibility. However, localised itching is rarely caused by a systemic process and the observed association was only significant when subjects reported having rash in specific body parts commonly affected by atopic dermatitis. This is the first time skin allergies have been characterised in such a detail in the study of pancreatic cancer risk. While we cannot discard this result may be due to chance, future studies should be encouraged to replicate this finding.

The mechanisms underlying the association between atopic diseases and PDAC risk are largely unknown. This remains an important area of study because it may provide opportunities for disease prevention. The contribution of a hyperactive immune system in individuals with atopic conditions, characterised by sustained elevated $\operatorname{IgE}$ levels, 36 has been proposed. Furthermore, susceptibility and severity of asthma and allergies are known to be affected by genetic factors and gene-environment interactions.37,38 A recent study exploring single-nucleotide polymorphism in 56 allergy-related candidate genes suggested that certain genetic variants may be associated with a reduction of pancreatic cancer risk.39 More studies will help us to understand the role of genetics in these associations. Additionally, it has been reported that the anti-allergic drug cromolyn can inhibit proliferation and invasion of human pancreatic cancer cells in vitro and tumour growth in mice.40 The potential confounding of treatment for allergy or asthma was previously assessed and only minimal negative confounding effect for some medications was reported.25 Future studies are needed to corroborate and extend these findings. Unknown exposures could also be relevant since individuals suffering from atopic diseases may avoid 
Gomez-Rubio, P., Zock, J.P., Rava, M., Marquez, M., Sharp, L., Hidalgo, M., Carrato, A., Ilzarbe L., Michalski, C., Molero, X., Farré, A., Perea, J., Greenhalf, W., O’Rorke, M., Tardón, A., Gress, T., Barbera, V., Crnogorac-Jurcevic, T., Dominguez-Munoz, E., Munoz-Bellvis, L., Alvarez-Iłrturi,7 C., Balcells, J., Barneo, L., Costello, E., Guillen-Ponce, C., Kleeff, J., Kong, B., Lawlor, R., LP̈hlve M., Mora, J., Murray, L., O'Driscoll, D., Pelaez, P., Poves, I., Scarpa, A., Real, F.X., Malats, N. Reduced risk of pancreatic cancer associated with asthma and nasal allergies. Gut: 2017, 66(2), 314-322

specific exposures or lifestyles that could be associated with PDAC development. Moreover, a reduced incidence of asthma and nasal allergies has been associated with Porphyromonas gingivalis, 41 a bacteria involved in the causation of caries,42that has been associated with high PDAC risk,43 suggesting potential confounding effect. Importantly, we considered self-reported periodontitis in our initial analysis and did not observe any confounding effect. The analysis of the specific oral microbiota using state-of-the-art metagenetic studies should contribute to unravel the relationship between these factors.

One of the major strengths of this study is the largest sample size of cases ever used to test the association between atopic diseases and PDAC risk. Nevertheless, some stratified analyses may be impaired because of lack of power, warranting further consideration. The fact that the association of PDAC with smoking status in our study (OR 1.67, 95\% CI 1.32 to 2.11) resulted in expected estimates44 supports the internal validity of the PanGenEU study. Atopic diseases constitute a syndromic constellation and are a heterogeneous group of diseases. In this study, we aimed to thoroughly characterise three major atopic conditions using data obtained through personal interviews conducted by trained monitors that applied the same structured questionnaire. A major concern with self-reported medical conditions is potential misclassification and bias. The inverse associations observed make the latter issue less likely. In addition, the questionnaire used here has been previously validated and includes a wide set of questions on specific symptoms for a more accurate assessment of these phenotypes. This detailed information allowed us to perform the most exhaustive analysis of the association between PDAC and atopic diseaserelated factors reported until now. The study population has been homogeneously recruited in centres from four European countries. While the focus of this study was subject-level factors, we also accounted for country-level differences since prevalence of PDAC varies between countries and both country-level and individuallevel factors may contribute to this heterogeneity. Multilevel model showed a country-level median OR of 2.08 (variance $\sigma 2=0.59$ ), interpreted as the median OR of developing PDAC if two persons with similar covariates were chosen randomly from two different countries. This suggests that between-country effect may be an important factor to understand differences of PDAC risk.

Altogether, our study provides consistent evidence on the significant inverse association between PDAC and nasal allergies and asthma. These results point to the involvement of immune/inflammatory exposures in pancreas carcinogenesis and further support the notion that atopic diseases are associated with a reduced risk for cancer. Future studies should focus on potential key confounders of these associations, including country-level specific variables, and on exploring the underlying biological mechanism for the reduced risk of PDAC among subjects with nasal allergies and asthma.

Pancreas cancer is a complex disease. By disentangling its aetiological landscape and combining precise information on PDAC risk factors, including atopic diseases, we could build and validate risk prediction models that help discriminate those individuals from the population with a high risk of PDAC. Those subjects will deserve to be included in primary prevention interventions and in screening programmes. Furthermore, understanding the genetic mechanisms subjacent to the 
Gomez-Rubio, P., Zock, J.P., Rava, M., Marquez, M., Sharp, L., Hidalgo, M., Carrato, A., Ilzarbe. L., Michalski, C., Molero, X., Farré, A., Perea, J., Greenhalf, W., O’Rorke, M., Tardón, A., Gress, T., Barbera, V., Crnogorac-Jurcevic, T., Dominguez-Munoz, E., Munoz-Bellvis, L., Alvarez=Itrturi,7 C., Balcells, J., Barneo, L., Costello, E., Guillen-Ponce, C., Kleeff, J., Kong, B., Lawlor, R., Löhrve M., Mora, J., Murray, L., O'Driscoll, D., Pelaez, P., Poves, I., Scarpa, A., Real, F.X., Malats, N. Reduced risk of pancreatic cancer associated with asthma and nasal allergies. Gut: 2017, 66(2), 314-322

inverse association between atopic diseases and asthma might allow the development and implementation of primary prevention interventions by modifying the immunological status of the high-risk population as well as by identifying effective treatments for patients with pancreatic cancer.

\section{FOOTNOTES}

\section{Acknowledgements}

The authors acknowledge the coordinators, field and administrative workers, technicians and stu dy participants of the European Study into Digestive Illnesses and Genetics (PanGenEU) study.

\section{Contributors}

NM; PG-R, J-PZ, FXR, MR: design of the study; analysis and interpretation of the data; preparation of the manuscript; and review and approval of the manuscript. MM: design, organisation and coordination of the study; management of the data and databases. LS, MH, AC, LI, CM, XM, AF, JP, WG, MOR, AT, TG, VB, TC-J, EDM, LM-B, CA-U, JB, LB, EC, CG-P, JK, BK, RL, ML, JM, LM, DOD, PP, IP, AS: design of the study; recruitment of subjects; collection of biological samples; and review and approval of the manuscript.

\section{Funding}

The work was partially supported by Fondo de Investigaciones Sanitarias (FIS), Instituto de Salud Carlos III, Spain (\#PI11/01542, \#PI0902102, \#PI12/01635, \#PI12/00815); Red Temática de Investigación Cooperativa en Cáncer, Spain (\#RD12/0036/0034, \#RD12/0036/0050, \#RD12/0036/0073); European Cooperation in Science and Technology - COST Action \#BM1204: EUPancreas. Acción Especial de Genómica, Spain (\#GEN2001-4748-c05-03); EU-6FP Integrated Project (\#018771-MOLDIAG-PACA), EU-FP7-HEALTH (\#259737CANCERALIA, \#256974-EPC-TM-Net), Cancer Focus Northern Ireland and Department for Employment and Learning; and ALF (\#SLL20130022), Sweden. The funders had no role in study design, data collection and analysis, decision to publish or preparation of the manuscript.

Competing interests None declared.

Patient consent Obtained.

Ethics approval The study was approved by the local ethics committee of the participating centres.

Provenance and peer review Not commissioned; externally peer reviewed. Data sharing statement The data of the PanGenEU study are only available upon request and evaluation by the Study Steering Committee. Requests should be addressed to NM

\section{REFERENCES}

1 Rahib L, Smith BD, Aizenberg R, et al. Projecting cancer incidence and deaths to 2030: the unexpected burden of thyroid, liver, and pancreas cancers in the United States. Cancer Res 2014;74:2913-21.

2 Malvezzi M, Bertuccio P, Levi F, et al. European cancer mortality predictions for the 
Gomez-Rubio, P., Zock, J.P., Rava, M., Marquez, M., Sharp, L., Hidalgo, M., Carrato, A., Ilzarbe. L., Michalski, C., Molero, X., Farré, A., Perea, J., Greenhalf, W., O’Rorke, M., Tardón, A., Gress, T., Barbera, V., Crnogorac-Jurcevic, T., Dominguez-Munoz, E., Munoz-Bellvis, L., Alvarez-1łrturi, 7 C., Balcells, J., Barneo, L., Costello, E., Guillen-Ponce, C., Kleeff, J., Kong, B., Lawlor, R., LP̈hlve M., Mora, J., Murray, L., O'Driscoll, D., Pelaez, P., Poves, I., Scarpa, A., Real, F.X., Malats, N. Reduced risk of pancreatic cancer associated with asthma and nasal allergies. Gut: 2017, 66(2), 314-322

year 2014. Ann Oncol 2014;25:1650-6.

3 Hidalgo M, Cascinu S, Kleeff J, et al. Addressing the challenges of pancreatic cancer: future directions for improving outcomes. Pancreatology 2015;15:8-18. 4 Malka D, Hammel P, Maire F, et al. Risk of pancreatic adenocarcinoma in chronic pancreatitis. Gut 2002;51:849-52.

5 Li D. Diabetes and Pancreatic Cancer. Mol Carcinog 2012;51:64-74.

6 Gandini S, Lowenfels AB, Jaffee EM, et al. Allergies and the risk of pancreatic cancer: a meta-analysis with review of epidemiology and biological mechanisms. Cancer Epidemiol Biomarkers Prev 2005;14:1908-16.

7 Olson SH, Hsu M, Satagopan JM, et al. Allergies and risk of pancreatic cancer: a pooled analysis from the Pancreatic Cancer Case-Control Consortium. Am J Epidemiol 2013;178:691-700.

8 Gold E, Gordis L, Diener M, et al. Diet and other risk factors for cancer of the pancreas. Cancer 1985;55:460-7.

9 Mack TM, Yu MC, Hanisch R, et al. Pancreas cancer and smoking, beverage consumption, and past medical history. J Natl Cancer Inst 1986;76:49-60.

$10 \mathrm{McWhorter}$ WP. Allergy and risk of cancer. A prospective study using NHANESI followup data. Cancer 1988;62:451-5.

11 Mills PK, Beeson WL, Abbey DE, et al. Dietary habits and past medical history as related to fatal pancreas cancer risk among Adventists. Cancer 1988;61:

2578-85.

12 Farrow DC, Davis S. Risk of pancreatic cancer in relation to medical history and the use of tobacco, alcohol and coffee. Int J Cancer 1990;45:816-20.

13 Jain M, Howe G.R, Lous P. St. and MAB. Coffee and alcohol as determinants of risk of pancreatic cancer: a cas-control study from Toronto. Int J Cancer $1991 ; 47: 384-9$.

14 Bueno de Mesquita HB, Maisonneuve P, Moerman CJ, et al. Aspects of medical history and exocrine carcinoma of the pancreas: a population-based case-control study in the Netherlands. Int J Cancer 1992;52:17-23.

15 Kalapothaki V, Tzonou A, Hsieh CC, et al. Tobacco, ethanol, coffee, pancreatitis, diabetes mellitus, and cholelithiasis as risk factors for pancreatic carcinoma. Cancer Causes Control 1993;4:375-82.

16 Dai Q, Zheng W, Ji B, et al. Prior immunity-related medical conditions and pancreatic-cancer risk in Shanghai. Int J Cancer 1995;63:337-40.

17 Eriksson NE, Mikoczy Z, Hagmar L. Cancer incidence in 13811 patients skin tested for allergy. J Investig Allergol Clin Immunol 2005;15:161-6.

18 Silverman DT, Schiffman M, Everhart J, et al. Diabetes mellitus, other medical conditions and familial history of cancer as risk factors for pancreatic cancer. $\mathrm{Br} \mathrm{J}$ Cancer 1999;80:1830-7.

19 Stolzenberg-Solomon RZ, Pietinen P, Taylor PR, et al. A prospective study of medical conditions, anthropometry, physical activity, and pancreatic cancer in male smokers (Finland). Cancer Causes Control 2002;13:417-26.

20 Holly E, Eberle C, Bracci P. Prior history of allergies and pancreatic cancer in the San Francisco Bay area. Am J Epidemiol 2003;158:432-41.

21 Eppel A, Cotterchio M, Gallinger S. Allergies are associated with reduced pancreas cancer risk: a population-based case-control study in Ontario, Canada. Int J Cancer 2007;121:2241-5.

22 Olson SH, Orlow I, Simon J, et al. Allergies, variants in IL-4 and IL-4R alpha genes, and risk of pancreatic cancer. Cancer Detect Prev 2007;31:345-51.

23 Anderson LN, Cotterchio M, Gallinger S. Lifestyle, dietary, and medical history factors associated with pancreatic cancer risk in Ontario, Canada. Cancer Causes Control 2009;20:825-34.

24 Maisonneuve P, Lowenfels AB, Bueno-de-Mesquita HB, et al. Past medical history and pancreatic cancer risk: Results from a multicenter case-control study. Ann Epidemiol 2010;20:92-8. 
Gomez-Rubio, P., Zock, J.P., Rava, M., Marquez, M., Sharp, L., Hidalgo, M., Carrato, A., Ilzarbe. L., Michalski, C., Molero, X., Farré, A., Perea, J., Greenhalf, W., O’Rorke, M., Tardón, A., Gress, T., Barbera, V., Crnogorac-Jurcevic, T., Dominguez-Munoz, E., Munoz-Bellvis, L., Alvarez-Itrturi,7 C., Balcells, J., Barneo, L., Costello, E., Guillen-Ponce, C., Kleeff, J., Kong, B., Lawlor, R., LP̈hlve M., Mora, J., Murray, L., O'Driscoll, D., Pelaez, P., Poves, I., Scarpa, A., Real, F.X., Malats, N. Reduced risk of pancreatic cancer associated with asthma and nasal allergies. Gut: 2017, 66(2), 314-322

25 Cotterchio M, Lowcock E, Hudson TJ, et al. Association between allergies and risk of pancreatic cancer. Cancer Epidemiol Biomarkers Prev 2014;23:469-80.

26 Turner MC, Chen Y, Krewski D, et al. Cancer mortality among US men and women with asthma and hay fever. Am J Epidemiol 2005;162:212-21.

27 Sunyer J, Basagaña X, Burney P, et al. International assessment of the internal consistency of respiratory symptoms. Am J Respir Crit Care Med 2000;162:930-5. 28 Burney PG, Laitinen L a, Perdrizet S, et al. Validity and repeatability of the IUATLD (1984) Bronchial Symptoms Questionnaire: an international comparison. Eur Respir J1989;2:940-5.

29 Stekhoven DJ, Bühlmann P. MissForest-nonparametric missing value imputation for mixed-type data. Bioinformatics 2012;28:112-18.

30 Merlo J, Chaix B, Ohlsson $\mathrm{H}$, et al. A brief conceptual tutorial of multilevel analysis in social epidemiology: using measures of clustering in multilevel logistic

regression to investigate contextual phenomena. J Epidemiol Community Heal 2006;60:290-7.

31 R Core Team. R: a language and environment for statistical computing. R Found.

Stat. Comput. 2014. http://www.r-project.org/

32 Olson SH, Hsu M, Wiemels JL, et al. Serum immunoglobulin e and risk of pancreatic cancer in the prostate, lung, colorectal, and ovarian cancer screening trial. Cancer Epidemiol Biomarkers Prev 2014;23:1414-20.

33 Fu SL, Pierre J, Smith-Norowitz TA, et al. Immunoglobulin E antibodies from pancreatic cancer patients mediate antibody-dependent cell-mediated cytotoxicity against pancreatic cancer cells. Clin Exp Immunol 2008;153:401-9.

34 Holly EA, Chaliha I, Bracci PM, et al. Signs and symptoms of pancreatic cancer: a population-based case-control study in the San Francisco Bay area. Clin Gastroenterol Hepatol 2004;2:510-17.

35 Karnath B. Pruritus: A sign of underlying disease. Hosp Physician 2005;41:25-9.

36 Josephs DH, Spicer JF, Corrigan CJ, et al. Epidemiological associations of allergy, IgE and cancer. Clin Exp Allergy 2013;43:1110-23.

37 Rava M, Smit L a M, Nadif R. Gene-environment interactions in the study of asthma in the postgenomewide association studies era. Curr Opin Allergy Clin Immunol 2015;15:70-8.

38 Ober C, Yao T. The genetics of asthma and allergic disease: a 21st century perspective. Immunol Rev 2011;242:10-30.

39 Cotterchio M, Lowcock E, Bider-Canfield Z, et al. Association between variants in atopy-related immunologic candidate genes and pancreatic cancer risk. PLoS ONE 2015;10:e0125273.

40 Arumugam T, Ramachandran V, Logsdon CD. Effect of Cromolyn on S100P interactions with RAGE and pancreatic cancer growth and invasion in mouse models. J Natl Cancer Inst 2006;98:1806-18.

41 Arbes Jr S, Sever M, Vaughn B, et al. Oral pathogens and allergic disease: results from the Third National Health and Nutrition Examination Survey. J Allergy Clin Immunol 2006;118:1169-75.

42 Mysak J, Podzimek S, Sommerova P, et al. Porphyromonas gingivalis:

Major Periodontopathic Pathogen Overview. J Immunol Res 2014;2014:

476068.

43 Michaud DS, Izard J, Wilhelm-Benartzi CS, et al. Plasma antibodies to oral bacteria and risk of pancreatic cancer in a large European prospective cohort study. Gut 2013;62:1764-70.

44 Bosetti C, Lucenteforte E, Silverman DT, et al. Cigarette smoking and pancreatic cancer: an analysis from the International Pancreatic Cancer Case-Control

Consortium (Panc4). Ann Oncol 2012;23:1880-8. 
Gomez-Rubio, P., Zock, J.P., Rava, M., Marquez, M., Sharp, L., Hidalgo, M., Carrato, A., Ilzarbe L., Michalski, C., Molero, X., Farré, A., Perea, J., Greenhalf, W., O’Rorke, M., Tardón, A., Gress, T., Barbera, V., Crnogorac-Jurcevic, T., Dominguez-Munoz, E., Munoz-Bellvis, L., Alvarez-Iłeturi,7 C., Balcells, J., Barneo, L., Costello, E., Guillen-Ponce, C., Kleeff, J., Kong, B., Lawlor, R., LP̈hrVe M., Mora, J., Murray, L., O'Driscoll, D., Pelaez, P., Poves, I., Scarpa, A., Real, F.X., Malats, N. Reduced risk of pancreatic cancer associated with asthma and nasal allergies. Gut: 2017, 66(2), 314-322

\section{TABLES AND FIGURES}

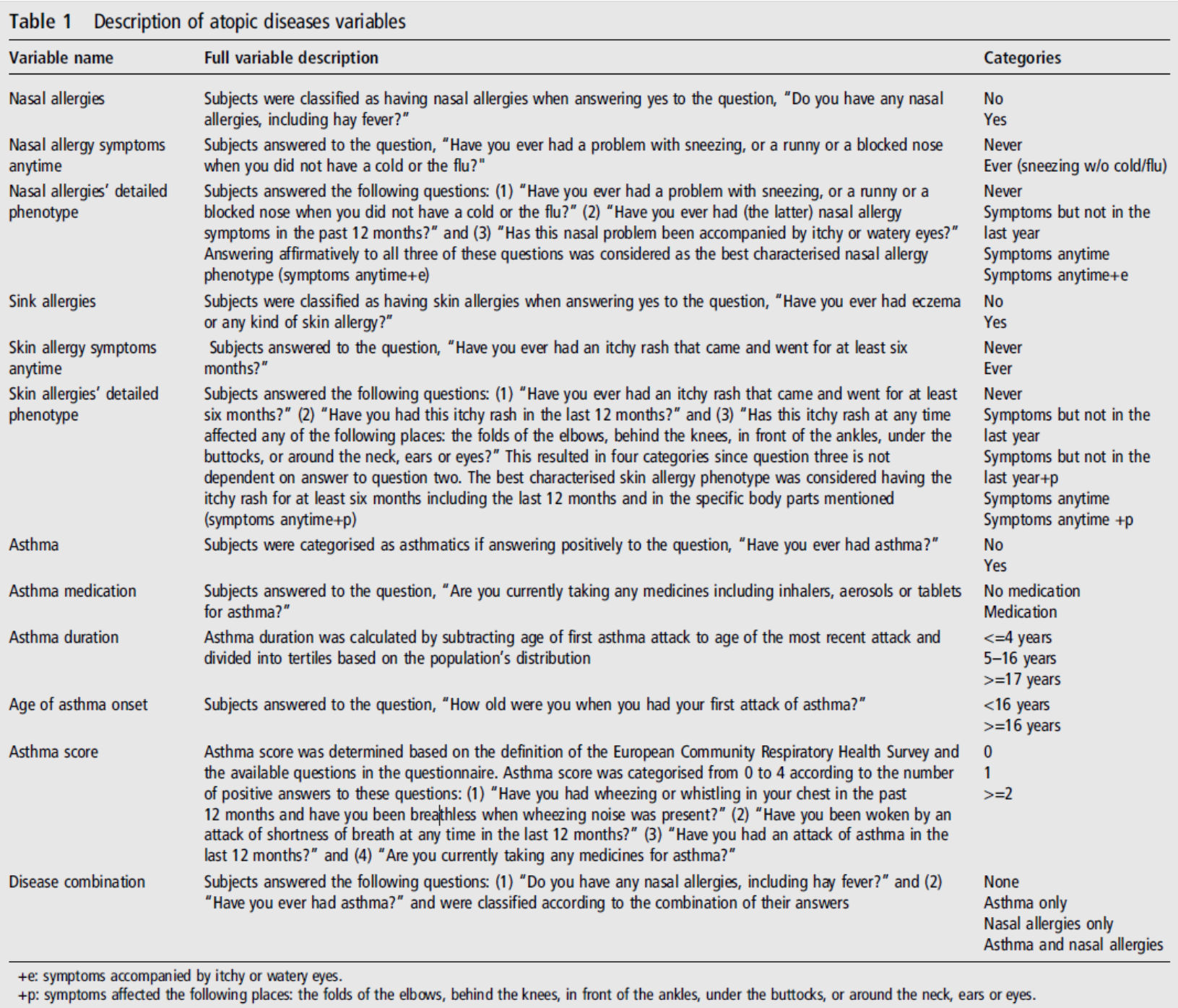


Gomez-Rubio, P., Zock, J.P., Rava, M., Marquez, M., Sharp, L., Hidalgo, M., Carrato, A., Ilzarbe, L., Michalski, C., Molero, X., Farré, A., Perea, J., Greenhalf, W., O’Rorke, M., Tardón, A., Gress, T., Barbera, V., Crnogorac-Jurcevic, T., Dominguez-Munoz, E., Munoz-Bellvis, L., Alvarez=\$trturi,7 C., Balcells, J., Barneo, L., Costello, E., Guillen-Ponce, C., Kleeff, J., Kong, B., Lawlor, R., Lק̈hkve M., Mora, J., Murray, L., O'Driscoll, D., Pelaez, P., Poves, I., Scarpa, A., Real, F.X., Malats, N. Reduced risk of pancreatic cancer associated with asthma and nasal allergies. Gut: 2017, 66(2), 314-322

Table 2 Characteristics of the study

\begin{tabular}{|c|c|c|c|c|}
\hline & \multicolumn{2}{|l|}{ Cases } & \multicolumn{2}{|l|}{ Controls } \\
\hline & $N=1297$ & $\%$ & $N=1024$ & $\%$ \\
\hline \multicolumn{5}{|l|}{ County } \\
\hline England & 126 & 9.7 & 22 & 2.1 \\
\hline Germany & 142 & 10.9 & 110 & 10.7 \\
\hline leland & 173 & 133 & 290 & 283 \\
\hline Spain & 856 & 66.0 & 602 & 58.8 \\
\hline \multicolumn{5}{|l|}{$\operatorname{sex}^{*}$} \\
\hline Female & 565 & 43.6 & 487 & 47.6 \\
\hline Male & 732 & 56.4 & 537 & 52.4 \\
\hline \multicolumn{5}{|l|}{ Age* } \\
\hline Mean (SD) & $652(12)$ & & $652(13.3)$ & \\
\hline$<=54$ & 237 & 18.3 & 220 & 21.5 \\
\hline $55-64$ & 322 & 24.8 & 215 & 21.0 \\
\hline $65-74$ & 446 & 34.4 & 313 & 30.6 \\
\hline$x=75$ & 292 & 22.5 & 276 & 27.0 \\
\hline \multicolumn{5}{|c|}{ Years of education } \\
\hline Mean (SD) & $112(6.21)$ & & $11(5.57)$ & \\
\hline$<=9$ & 380 & 293 & 329 & 32.1 \\
\hline $9.1-13$ & 402 & 31.0 & 324 & 31.6 \\
\hline$x=13.1$ & 382 & 29.5 & 308 & 30.1 \\
\hline NA & 133 & 10.3 & 63 & 62 \\
\hline \multicolumn{5}{|l|}{ BM } \\
\hline Mean (SD) & $27(4.73)$ & & $27(5)$ & \\
\hline$<=24.9$ & 454 & 35.0 & 360 & 352 \\
\hline $25-29.9$ & 493 & 38.0 & 390 & 38.1 \\
\hline$x=30$ & 268 & 20.7 & 210 & 20.5 \\
\hline NA & 82 & 63 & 64 & 63 \\
\hline \multicolumn{5}{|c|}{ Cigasette smokng* } \\
\hline Never & 561 & 433 & 524 & 512 \\
\hline forme & 391 & 30.1 & 303 & 29.6 \\
\hline Curtent & 345 & 26.6 & 197 & 192 \\
\hline \multicolumn{5}{|c|}{ Tertiles of padk/pars* } \\
\hline$<=20.9$ & 219 & 16.9 & 186 & 182 \\
\hline $21-44.9$ & 273 & 21.0 & 156 & 152 \\
\hline$x=45$ & 244 & 18.8 & 158 & 15.4 \\
\hline \multicolumn{5}{|c|}{ Alcohol consumption } \\
\hline No & 363 & 28.0 & 315 & 30.8 \\
\hline Yes & 918 & 70.8 & 686 & 67.0 \\
\hline NA & 16 & 12 & 23 & 22 \\
\hline \multicolumn{5}{|l|}{ Peribdantits } \\
\hline No & 991 & 76.4 & 808 & 78.9 \\
\hline Yes & 210 & 16.2 & 149 & 14.6 \\
\hline NA & 96 & 7.4 & 67 & 6.5 \\
\hline \multicolumn{5}{|l|}{ Diabetes* } \\
\hline No & 929 & 71.6 & 891 & 87.0 \\
\hline$<=2$ yess & 156 & 12.0 & 22 & 2.1 \\
\hline$>2$ years & 212 & 163 & 111 & 10.8 \\
\hline \multicolumn{5}{|c|}{ Chronic pancreattis* } \\
\hline No & 1289 & 99.4 & 1023 & 99.9 \\
\hline Yes & 8 & 0.6 & 1 & 0.1 \\
\hline
\end{tabular}


Gomez-Rubio, P., Zock, J.P., Rava, M., Marquez, M., Sharp, L., Hidalgo, M., Carrato, A., Ilzarbe L., Michalski, C., Molero, X., Farré, A., Perea, J., Greenhalf, W., O’Rorke, M., Tardón, A., Gress, T., Barbera, V., Crnogorac-Jurcevic, T., Dominguez-Munoz, E., Munoz-Bellvis, L., Alvarez-lurturi, 7 C., Balcells, J., Barneo, L., Costello, E., Guillen-Ponce, C., Kleeff, J., Kong, B., Lawlor, R., LP̈hlve M., Mora, J., Murray, L., O'Driscoll, D., Pelaez, P., Poves, I., Scarpa, A., Real, F.X., Malats, N. Reduced risk of pancreatic cancer associated with asthma and nasal allergies. Gut: 2017, 66(2), 314-322

Table 3 Multilevel logistic regression modek for nasal allergies skin allergies, and asthma and pancreatic cancer

\begin{tabular}{|c|c|c|c|c|c|c|}
\hline & \multicolumn{6}{|c|}{ Multivariate* } \\
\hline & \multicolumn{2}{|l|}{ Cases } & \multicolumn{2}{|l|}{ Controls } & \multirow[b]{2}{*}{ OR $(95 \% \mathrm{CI})$} & \multirow[b]{2}{*}{$p$ Trend } \\
\hline & $N=1297$ & $\%$ & $N=1024$ & $\%$ & & \\
\hline \multicolumn{7}{|c|}{ Do you hare any nasal allergles, hoduding hay fever?t } \\
\hline No & 1111 & 85.7 & 812 & 79.3 & 1 & \\
\hline Yes & 186 & 143 & 212 & 20.7 & $0.66(0.52$ b 0.83$)$ & \\
\hline \multicolumn{7}{|l|}{ Nasal allegy symptoms anytmet } \\
\hline Never & 922 & 71.1 & 645 & 63.0 & 1 & \\
\hline Ever (sneezing wo coldflu)t & 375 & 28.9 & 379 & 37.0 & $0.73(0.6$ to 0.87$)$ & \\
\hline \multicolumn{7}{|l|}{ Nasal allexgies' detailed phenotype } \\
\hline Symptoms but not in the last year & 82 & 63 & 59 & 5.8 & 1.09 (10.76 b 1.59) & \\
\hline Symptoms anytme & 148 & 11.4 & 151 & 14.7 & $0.74(0.57$ b 0.96$)$ & \\
\hline \multirow[t]{2}{*}{ Symptoms anytmetet } & 145 & 112 & 169 & 16.5 & $0.59(0.46$ b 0.77$)$ & \\
\hline & & & & & & 0.00003 \\
\hline \multicolumn{7}{|c|}{ Have you ever had eczena or any kind of skn allergy?t } \\
\hline No & 997 & 76.9 & 769 & 75.1 & 1 & \\
\hline Yes & 300 & 23.1 & 255 & 24.9 & $0.95(0.78$ b 1.17$)$ & \\
\hline \multicolumn{7}{|l|}{ Skin allergy symptoms anytimet } \\
\hline Never & 1091 & 84.1 & 890 & 86.9 & 1 & \\
\hline Ever (roch duing 6 monts) $\dagger$ & 206 & 15.9 & 134 & 13.1 & $133(1.04$ b 1.69) & \\
\hline \multicolumn{7}{|l|}{ Skin allergles' detalled phenotype } \\
\hline Symptoms but not in the last year & 38 & 2.9 & 41 & 4.0 & $0.84(0.52$ b 134$)$ & \\
\hline Symptoms but not in the last yeart $p 5$ & 26 & 2.0 & 22 & 2.1 & $0.86(0.47$ b 1.58) & \\
\hline Symptoms anytme & 52 & 4.0 & 40 & 3.9 & $12(0.77$ b 1.87$)$ & \\
\hline \multirow[t]{2}{*}{ Symptoms anytme+pf } & 90 & 6.9 & 31 & 3.0 & $2.47(1.6$ to 3.81$)$ & \\
\hline & & & & & & 0.0005 \\
\hline \multicolumn{7}{|l|}{ Have you ever had asthma?t } \\
\hline No & 1209 & 932 & 914 & 89.3 & 1 & \\
\hline Yes & 88 & 6.8 & 110 & 10.7 & 0.64 (0.47 b 0.88) & \\
\hline No medicatont & 42 & 32 & 31 & 3.0 & $1.09(0.67$ b 1.79$)$ & \\
\hline Medicatont & 46 & 3.5 & 79 & 7.7 & $0.47(0.31$ b 0.69$)$ & \\
\hline \multicolumn{7}{|l|}{ Asthma duration (years)t } \\
\hline$\ll 4$ & 36 & 2.8 & 27 & 2.6 & $122(0.72$ b 2.07$)$ & \\
\hline $5-16$ & 26 & 2.0 & 35 & 3.4 & $0.59(0.35$ b 1.04$)$ & \\
\hline \multirow[t]{2}{*}{$>=17$} & 26 & 2.0 & 48 & 4.7 & $0.39(0.24$ D 0.65$)$ & \\
\hline & & & & & & 0.0002 \\
\hline \multicolumn{7}{|l|}{ Age of asthma orset (years)t } \\
\hline$<16$ & 14 & 1.1 & 19 & 1.9 & $0.61(0.29$ D 1.27$)$ & \\
\hline$>=16$ & 74 & 5.7 & 91 & 8.9 & 0.65 (10.47 b 0.91) & \\
\hline \multicolumn{7}{|l|}{ Asthma scone $e^{* *} \dagger$} \\
\hline 0 & 1053 & 82.0 & 794 & 77.5 & 1 & \\
\hline 1 & 173 & 133 & 141 & 13.8 & $0.96(0.75$ b 1.24$)$ & \\
\hline \multirow[t]{2}{*}{$<=2$} & 61 & 4.7 & 89 & 8.7 & $0.49(0.34$ b 0.71$)$ & \\
\hline & & & & & & 0.0002 \\
\hline \multicolumn{7}{|l|}{ Disease combinationt } \\
\hline None & 1055 & 813 & 741 & 72.4 & 1 & \\
\hline Asthma only & 56 & 43 & $n$ & 6.9 & $0.55(0.38$ t 0.81$)$ & \\
\hline Nasal alleggies only & 154 & 11.9 & 173 & 16.9 & $0.62(10.48$ ( 0.79$)$ & \\
\hline Asthma and nasal allengies & 32 & 2.5 & 39 & 3.8 & $0.69(0.42$ b 1.13) & \\
\hline \multicolumn{7}{|c|}{ 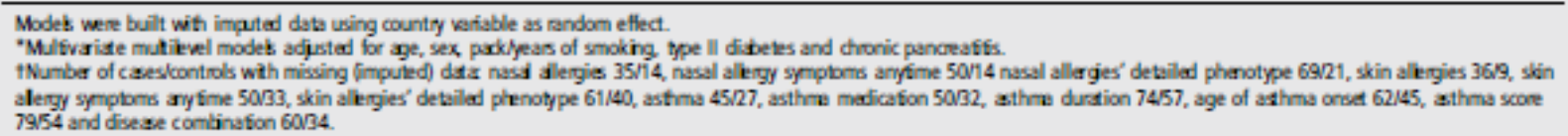 } \\
\hline
\end{tabular}


Gomez-Rubio, P., Zock, J.P., Rava, M., Marquez, M., Sharp, L., Hidalgo, M., Carrato, A., Ilzarbe. L., Michalski, C., Molero, X., Farré, A., Perea, J., Greenhalf, W., O’Rorke, M., Tardón, A., Gress, T., Barbera, V., Crnogorac-Jurcevic, T., Dominguez-Munoz, E., Munoz-Bellvis, L., Alvarez=Iłrturi,7 C., Balcells, J., Barneo, L., Costello, E., Guillen-Ponce, C., Kleeff, J., Kong, B., Lawlor, R., LP̈hrVe M., Mora, J., Murray, L., O'Driscoll, D., Pelaez, P., Poves, I., Scarpa, A., Real, F.X., Malats, N. Reduced risk of pancreatic cancer associated with asthma and nasal allergies. Gut: 2017, 66(2), 314-322

Figure 1 Meta-analysis of casecontrol studies of the association between asthma and pancreatic cancer risk. The pooled estimate and $95 \% \mathrm{Cl}$ for a random-effects (RE) model is shown in the bottom of the figure. Non-significant heterogeneity was $\mathrm{p}=0.36)$. NA, not available. observed between studies $\left(I^{2}=13.5 \%\right.$,

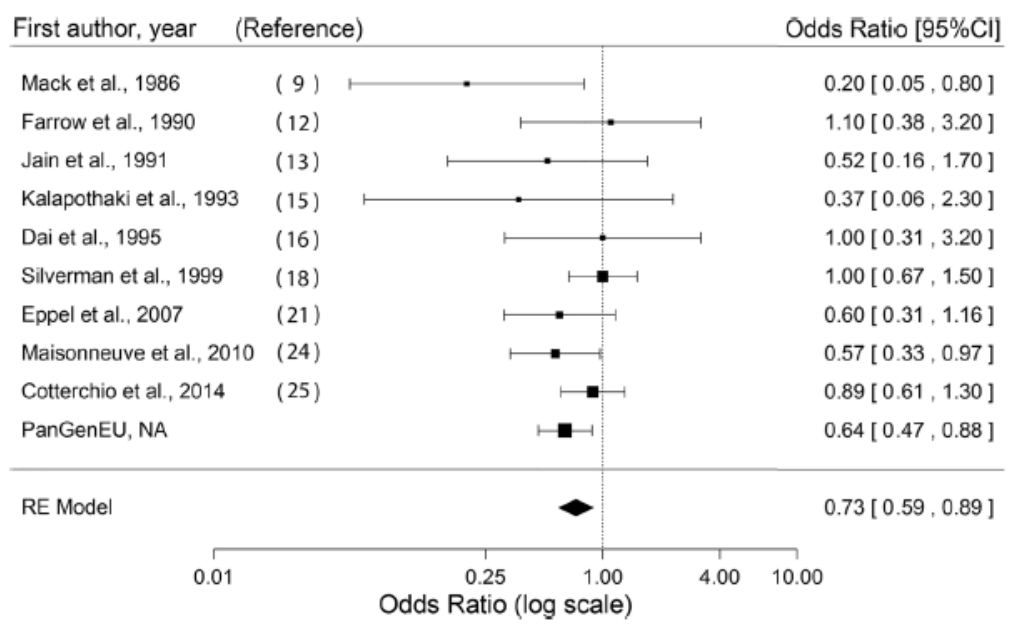

Figure 2 Meta-analysis of casecontrol studies of the association between nasal allergies and pancreatic cancer risk. The pooled estimate and $95 \% \mathrm{Cl}$ for a random-effects (RE) model is shown in the bottom of the figure. Significant heterogeneity was observed between studies $\left(I^{2}=50.99 \%\right.$, $\mathrm{p}=0.035)$. NA, not available.

Figure 3 Meta-analysis of casecontrol studies of the association between skin allergies and pancreatic cancer risk. The pooled estimate and $95 \% \mathrm{Cl}$ for a random-effects (RE) model is shown in the bottom of the figure. Non-significant heterogeneity was observed between studies $\left(I^{2}=30 \%, p=0.13\right)$. NA, not available.

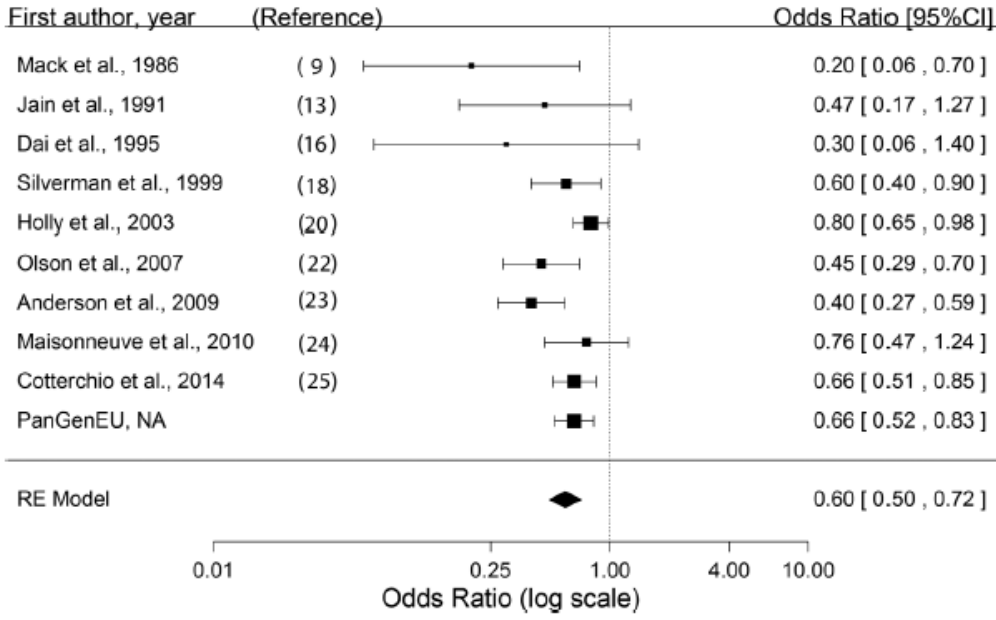

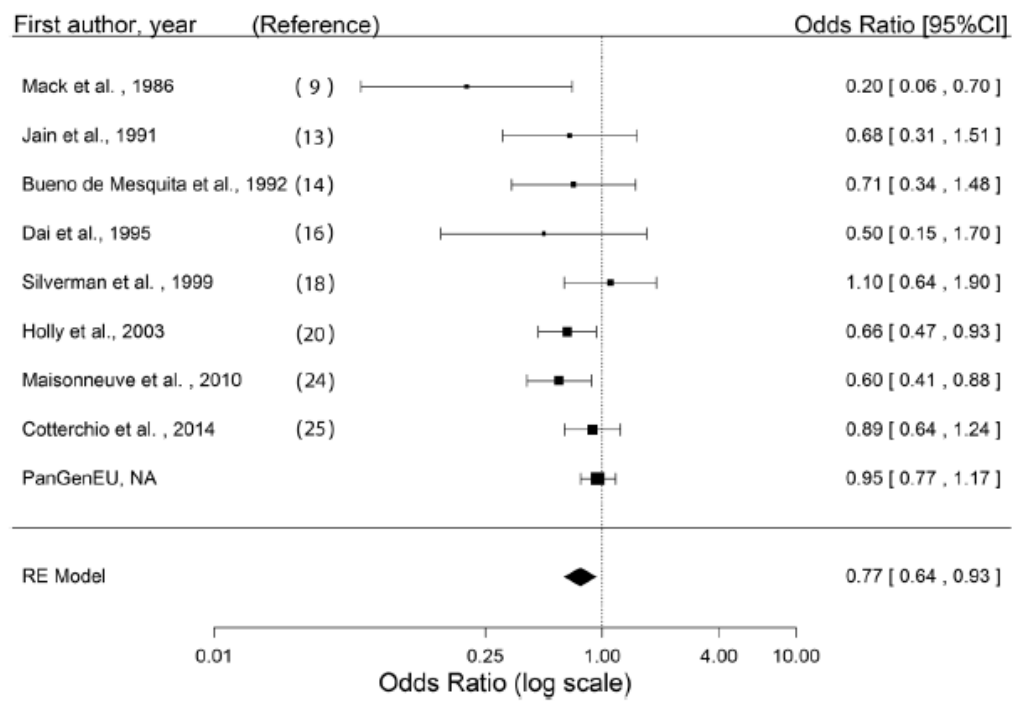

